\title{
Variability of Nitrate Concentrations in the Shallow Ground Water in a Selected Area of the San Luis Valley, South-Central Colorado
}

$\tau_{\text {he San Luis Valley is a high, arid }}$ valley in south-central Colorado (fig. 1) bounded by the Sangre de Cristo Mountains to the east and the San Juan Mountains to the west. The valley has been farmed extensively for more than 100 years. A study done in the late 1960's (Emery and others,

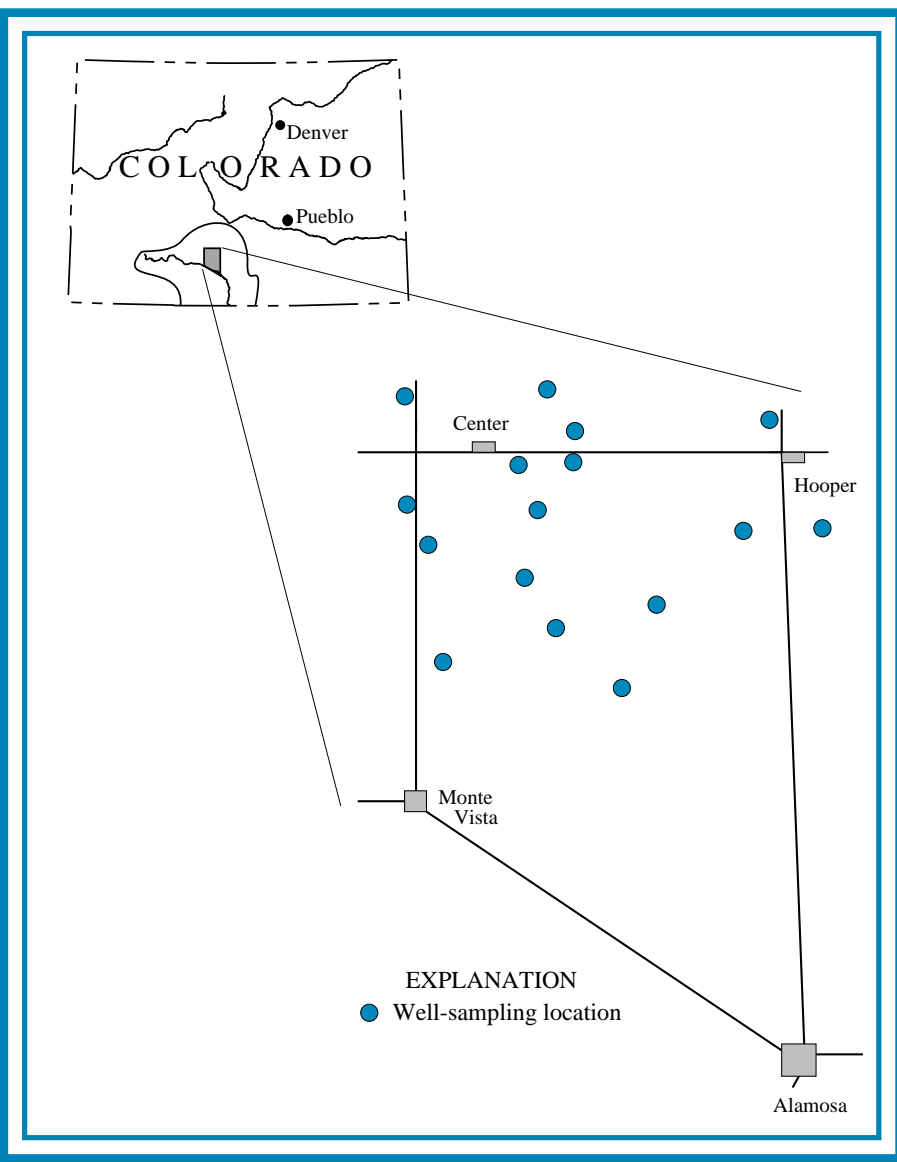

Figure 1. Location of the study area and well-sampling locations.

1973) indicated that nitrate concentrations in the water of the unconfined aquifer in an area near Center, Colorado, exceeded the maximum contaminant level (MCL) for drinking water of 10 milligrams per liter (mg/L) as nitrogen. Previous studies (Edelmann and Buckles, 1984; Austin, 1993) indicated that the extent of area near Center having elevated nitrate concentrations might have changed since the late 1960's. In recent years, water, nutrient, and pesticide-management practices have been developed, implemented, and evaluated at various locations in the valley. The intent of these management practices is to optimize the management of water, nutrients, and pesticides and to decrease the transport of agricultural fertilizers and pesticides to the ground water. Although several studies of nitrate concentrations in ground water in the San Luis Valley have been done, differences in the types and number of wells sampled, the time of year sampling was done, sampling protocols, and laboratory analytical meth-

ods limit the degree to which results from these studies can be compared.

In 1994, the U.S. Geological Survey, in cooperation with the Rio
Grande Water Conservation District, the Center Soil Conservation District, and the San Luis Valley Resource Conservation and Development Council, began a study to evaluate the variability of nitrate concentrations in the shallow ground water. The possible sources of nitrate in the shallow ground water also were investigated. This fact sheet describes variability of nitrate concentrations during 1994 and 1995, factors affecting variability, and possible sources of nitrate to the shallow ground-water system.

\section{VARIABILITY OF NITRATE CONCENTRATIONS}

Sixteen wells in the study area (fig. 1) were sampled four times in 1994 and four times in 1995 in order to assess the spatial and temporal variability of nitrate concentrations (reported

- Nitrate concentrations in water from an individual well can vary substantially depending upon period of sample collection.

$\Rightarrow$ Nitrate concentrations were highly variable from well to well.

$\Rightarrow$ Variations in nitrate concentrations among annual samples collected during the same month were generally smaller than variations between different sampling periods during the same irrigation season. 
as nitrogen). The wells were completed in the top 10 feet of the shallow, unconfined aquifer. Samples were collected before the irrigation season in April or May and during the irrigation season in July, August, and September.

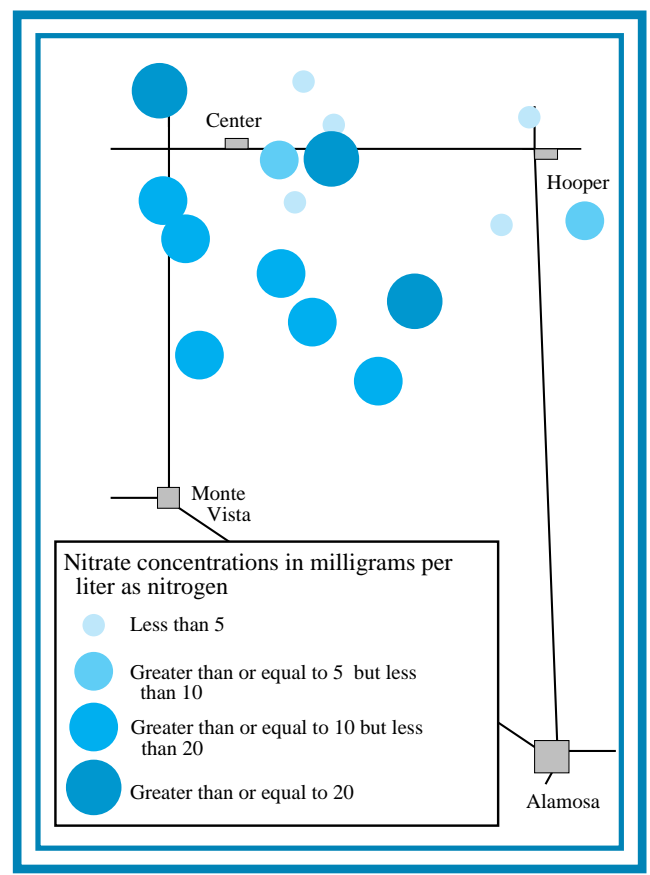

Figure 2. Average nitrate concentrations in individual wells during 1994 and 1995.

Average nitrate concentrations at the top of the unconfined aquifer were highly variable among individual wells (fig. 2) sampled in 1994 and 1995. Between May 1994 and September 1995, nitrate concentrations in the 128 samples collected from the 16 wells ranged from 0.07 to $72 \mathrm{mg} / \mathrm{L}$. The difference between the lowest nitrate concentration and the highest nitrate concentration among the 16 wells during any sampling period ranged from 38 to $71 \mathrm{mg} / \mathrm{L}$. Differences between the minimum and the maximum nitrate concentrations within individual wells among sampling periods ranged from 1.7 to 34 $\mathrm{mg} / \mathrm{L}$; differences were greater than or equal to $5 \mathrm{mg} / \mathrm{L}$ in 62 percent of the wells and were greater than or equal to $10 \mathrm{mg} / \mathrm{L}$ in 44 percent of the wells (fig. 3).
There was little consistency in the observed temporal variability of nitrate concentrations in the study area. The timing and magnitude of the variability was inconsistent from year to year in individual wells and from month to month in nearby wells. Figure 4 illustrates the wide range in the observed temporal variability of nitrate concentrations in selected wells. Although nitrate concentrations in subsequent months varied as much as $25 \mathrm{mg} / \mathrm{L}$ in well A, concentrations in well $\mathrm{D}$ varied less than $1.0 \mathrm{mg} / \mathrm{L}$.

\section{$\Rightarrow$ Nitrate concentrations might be affected by many} factors. These include (but are not limited to):

- the current nutrient and water-management practices at individual farms, which may vary from location to location;

- timing and amount of precipitation;

- differences in soil types;

- differences in rates and timing of recharge to the aquifer from the land surface;

- differences in uptake of nitrate due to different crop types, varieties, or rotations;

- cultural practices, such as tillage and residue management;

- differences in nitrogen transformation (denitrification) rates; and

- the elevation of the water table.

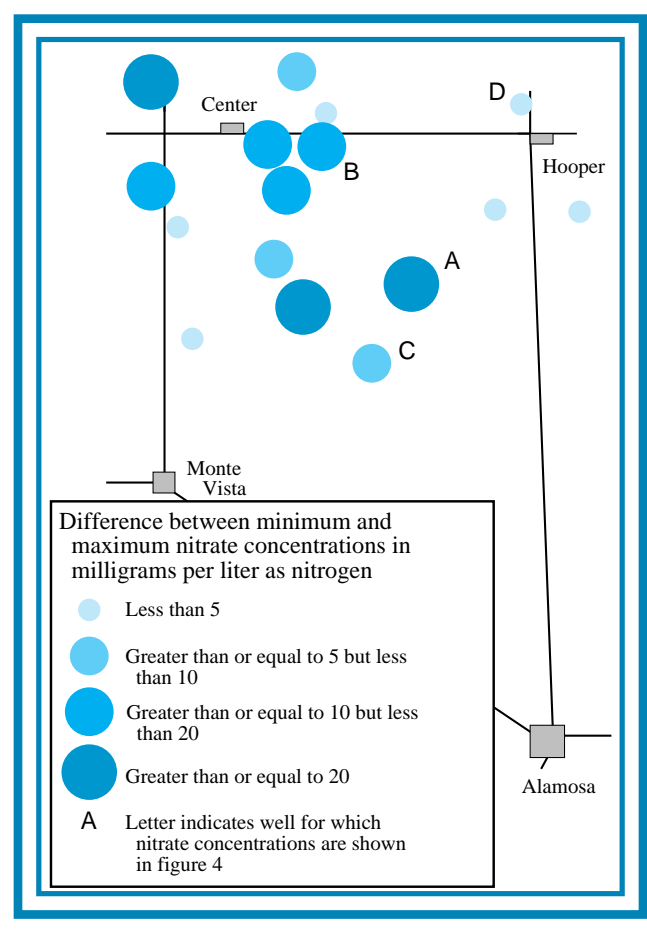

Figure 3. Ranges of differences between minimum and maximum nitrate concentrations in individual wells during 1994 and 1995.

\section{WHAT ARE THE SOURCES OF NITRATE?}

To evaluate possible sources of nitrate, ground-water samples collected during August 1994 and August 1995 were analyzed for nitrogen isotopes. Nitrogen isotope ratios $\left(\mathrm{N}^{15} / \mathrm{N}^{14}\right)$ have been used to indicate possible sources of nitrate (Komor and Anderson, 1993; Gellenbeck, 1994). Nitrogen isotope ratios between -2 and 6 generally are indicative of mineral fertilizer sources; nitrogen isotope ratios between 6 and 10 are indicative of mixed sources or removal of nitrogen from the water by the process of denitrification; and nitrogen isotope ratios greater than 10 generally are indicative of animal-waste sources (Tyler B. Coplen, U.S. Geological Survey, written commun., 1991).

In the study area, nitrogen isotope ratios ranged from 2.9 to 28.6; lower ratios were measured in the southern and western parts of the study area, and higher ratios were measured in the northern and eastern parts of the study 
area. Average nitrogen isotope ratios at 7 of the 16 wells were less than 6 ; average isotope ratios at 4 wells were greater than or equal to 6 but less than 10; and isotope ratios at 3 wells were greater than or equal to 10 (fig. 5). Nitrate concentrations at two wells were too low for isotope analysis. Although nitrogen isotope ratios

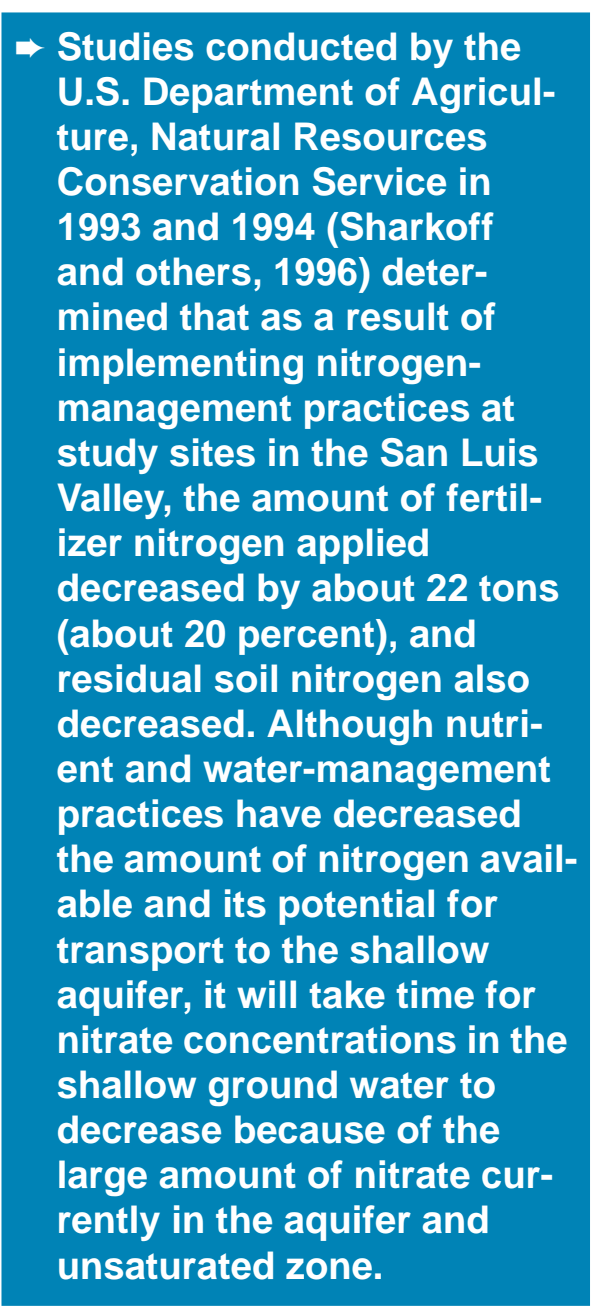

greater than 10 , which generally are indicative of animal wastes as a potential nitrate source, were measured at three wells in the study area, low dissolved-oxygen concentrations in the samples collected from the three wells, the presence of sufficient dissolved-organic carbon, and information on site history indicate denitrification probably resulted in the elevated isotope ratios. In the remaining 13 wells, dissolved-oxygen concentrations were higher and dissolved-organic-carbon concentra-

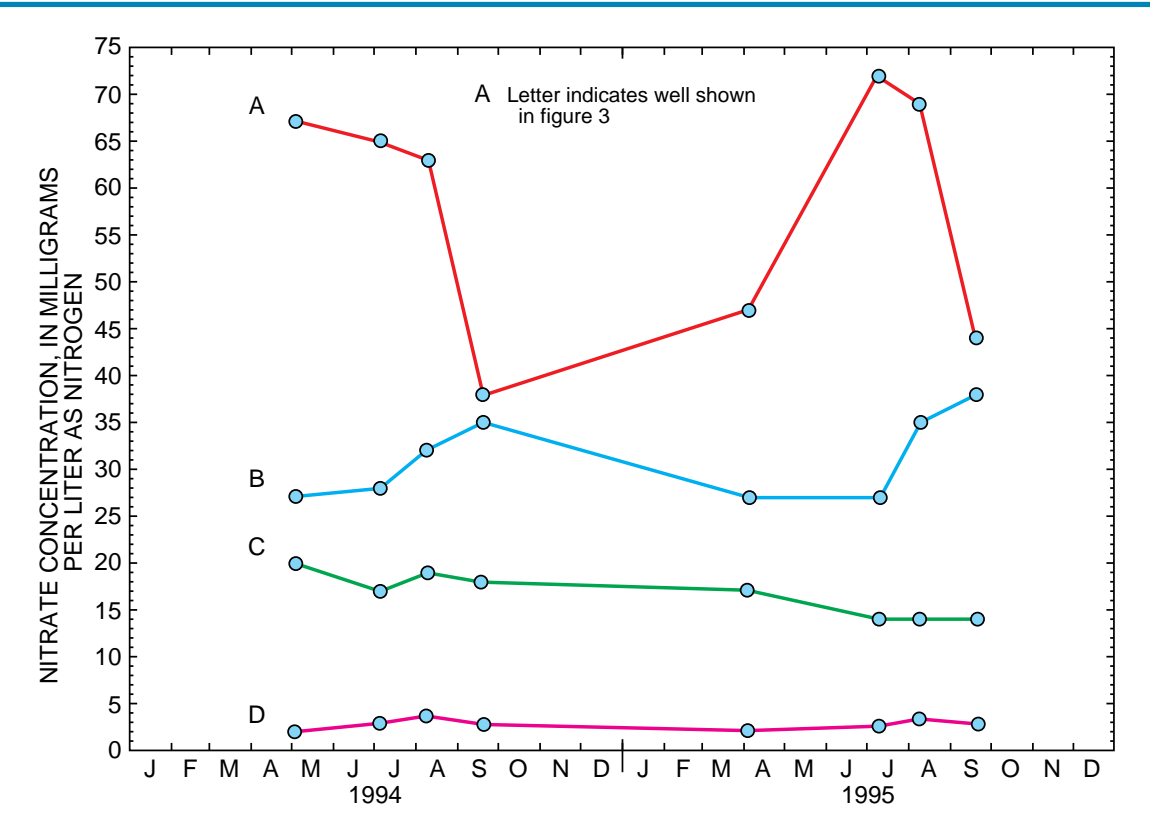

Figure 4. Variability of nitrate concentrations at selected wells.

tions were lower, inhibiting denitrification. Therefore, it is probable that mineral fertilizers and not organic nitrogen sources (for example, animal waste) are the primary source of nitrate in the shallow aquifer in the study area. This conclusion is supported by studies conducted by LeStrange (1995).

\section{CONCLUSIONS}

The spatial and temporal variability of nitrate concentrations in the shallow ground water of the San Luis Valley make an accurate evaluation of trends in nitrate concentrations difficult. In addition, the ability to accurately assess these trends has been hindered by inconsistencies in past and present sampling designs. Sampling a larger number of wells and incorporating consistent field and analytical methods would make trend detection more feasible. Additionally, the establishment of such a network would aid in the assessment of the cause-and-effect relations of nutrient management and nitrate concentrations.

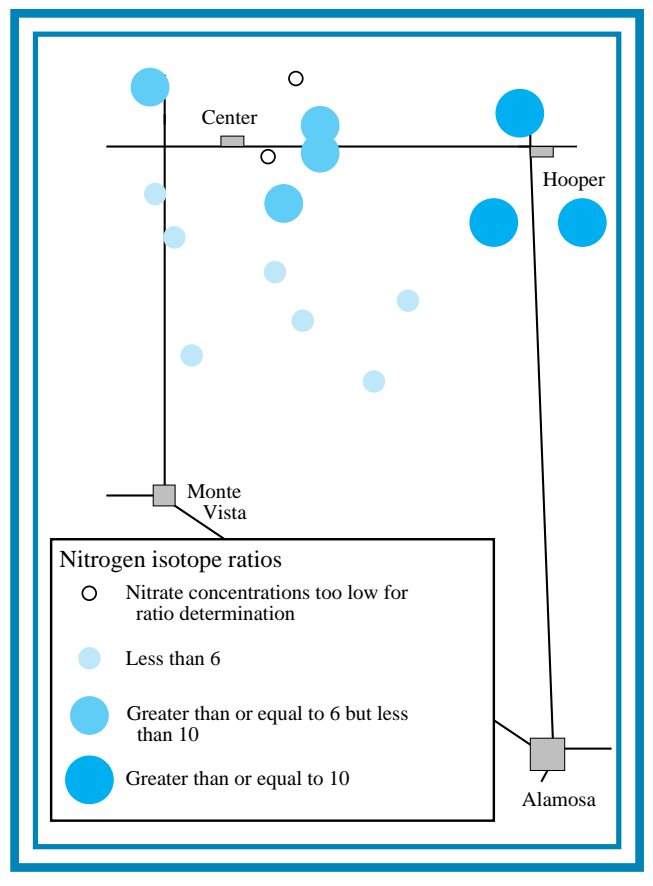

Figure 5. Average nitrogen isotope ratios, August 1994 and August 1995. 


\section{SELECTED REFERENCES}

Austin, Bradford, 1993, Ground water monitoring activities San Luis Valley unconfined aquifer 1993: Report to the Commissioner of Agriculture, Colorado Department of Agriculture, $24 \mathrm{p}$.

Edelmann, Patrick, and Buckles, D.R., 1984, Quality of ground water in agricultural areas of the San Luis Valley, southcentral Colorado: U.S. Geological Survey Water-

Resources Investigations Report 83-4281, 37 p.

Emery, P.H., Snipes, R.J., Dumeyer, J.M., and Klein, J.M., 1973, Water in the San Luis Valley, south-central Colorado: Denver, Colorado Water Conservation Board, Colorado Water Resources Circular 18, $26 \mathrm{p}$.

Gellenbeck, D.J., 1994, Isotopic compositions and sources of nitrate in ground water from western Salt River Valley, Arizona: U.S. Geological Survey Water-Resources Investigations Report 94-4063, 53 p.
Komor, S.C. and Anderson, H.W., Jr., 1993, Nitrogen isotopes as indicators of nitrate sources in Minnesota sand-plain aquifers: Ground Water, v. 31, no. 2, p. 260-270.

LeStrange, S.L., 1995, Identification of spatial patterns in nitrate leaching: Fort Collins, Colorado State University, unpublished Ph.D. dissertation, $97 \mathrm{p}$.

Sharkoff, J.L., Delgado, J.A., Follett, R.F., and Riggenbach, R.R., 1996, Nitrate leaching assessment of San Luis Valley Water Quality Demonstration Project sites, in Proceedings of the 13th Annual Potato/ Grain Conference, Monte Vista, Colo., February 13-15, 1996, p. 9-10. (Colorado State University Cooperative Extension, Alamosa, Colo.)

Siebenthal, C.E., 1910, Geology and water resources of the San Luis Valley, Colorado: U.S. Geological Survey Water-Supply Paper 240, $128 \mathrm{p}$.
For more information, please contact:

Subdistrict Chief

U.S. Geological Survey

201 W. 8th Street, Suite 200

Pueblo, CO 81003

(719) 544-7155

FAX (719) 544-7155

email:

dcain@cronos.usgs.gov
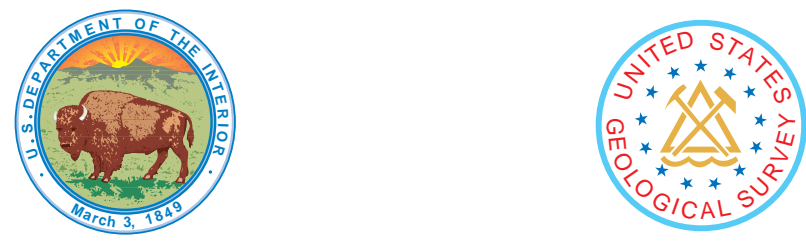